\title{
Two allele-specific PCR assays for screening epidermal growth factor receptor gene hotspot mutations in lung adenocarcinoma
}

\author{
REGINE DAHSE $^{1}$, ALEXANDER BERNDT $^{2}$, ANNE-KRISTIN DAHSE ${ }^{3}$ and HARTWIG KOSMEHL ${ }^{1}$ \\ ${ }^{1}$ Institute of Pathology, HELIOS Clinic Erfurt, Nordhäuser Strasse 74, D-99089 Erfurt; ${ }^{2}$ Institute of Pathology, \\ Friedrich Schiller University Jena, Ziegelmühlenweg 1, D-07740 Jena, Germany; ${ }^{3}$ School of Biological Sciences, \\ Victoria University of Wellington, P.O. Box 600, Wellington 6140, New Zealand
}

Received November 5, 2007; Accepted November 29, 2007

\begin{abstract}
In patients with non-small cell lung cancer, mutations in the EGFR tyrosine kinase domain have been associated with improved response to tyrosine kinase inhibitors such as gefitinib or erlotinib and prolonged survival. Two hotspot mutations located in exons 19 and 21 account for approximately $90 \%$ of EGFR mutations reported to date in lung adenocarcinoma. A Bi-PASA (bidirectional PCR amplification of specific alleles) assay for detecting the exon 19 deletion (codons 746-750) and an allele-specific PCR assay for the EGFR hotspot mutation L858R in exon 21 were designed. The assays were validated in normal control samples and in lung adenocarcinoma cell lines containing the mutation. The three-primer assay for the exon 21 point mutation and the four-primer assay for the exon 19 deletion were able to specifically discriminate wild-type and mutant DNA. The primer specificity was confirmed by genomic sequencing. The allele-specific PCR assays are fast and easy to perform in any routine PCR laboratory and no special equipment other than thermocyclers is required. They provide rapid, sensitive and cost-effective EGFR testing as part of standard lung cancer management for identifying patients who might clinically benefit from tyrosine kinase inhibitors. The Bi-PASA assay proved to be a suitable method to detect small deletions. Strategies in designing allele-specific primers described herein can be adapted to other screening assays for point mutations and small deletions.
\end{abstract}

\section{Introduction}

The epidermal growth factor receptor (EGFR) family of receptor tyrosine kinases (including EGFR/ErbB1, HER2/

Correspondence to: Dr Regine Dahse, HELIOS Klinikum Erfurt, Institute of Pathology, Nordhäuser Str. 74, D-99089 Erfurt, Germany E-mail: rdahse@erfurt.helios-kliniken.de

Key words: epidermal growth factor receptor, non-small cell lung cancer, tyrosine kinase inhibitor, allele-specific PCR, mutation screening
ErbB2, HER3/ErbB3, HER4/ErbB4) has proved to be a sensitive target for antitumor therapies. Small molecules that inhibit the EGFR tyrosine kinase domain have become effective drugs in the treatment of non-small cell lung cancer (NSCLC). Recent studies have identified a subset of NSCLC patients characterized clinicopathologically by female sex, non-smoking and adenocarcinoma histology with durable and dramatic responses to EGFR tyrosine kinase inhibitors and found an underlying association between mutations in the EGFR tyrosine kinase domain and drug-responsive NSCLC $(1,2)$. Several studies have also demonstrated that patients with EGFR mutation-positive tumors gain improved survival with tyrosine kinase inhibitory drugs compared with wild-type cases (3).

These heterozygous EGFR tyrosine kinase mutations, clustered within the ATP-binding pocket (4), cause ligandindependent activation of EGFR, while simultaneously increasing sensitivity to tyrosine kinase inhibitors. Compared with wild-type, mutant receptors preferentially activate survival pathways and alter downstream signaling (4). Two mutations account for approximately $90 \%$ of EGFR mutations reported to date in lung adenocarcinoma (5). An in-frame deletion of 9-24 nucleotides in exon 19 centered around codons 746-750 makes up $45-50 \%$ of mutations. The second most common mutation, found in up to $45 \%$ of cases with EGFR mutations, is a point mutation at nucleotide 2573 (CTG $\rightarrow$ CGG) in exon 21 that results in substitution of leucine by arginine at codon 858 (L858R) $(5,6)$. Although these gain of function EGFR mutations are rare outside NSCLC, they have been detected in cases of tyrosine kinase inhibitor-responsive ovarian cancer and small-cell lung cancer, as well as in untreated cases of colon cancer, head and neck cancer, and cholangiocarcinoma (6).

For current clinical practice in the care of lung cancer patients, simple screening assays for molecular predictors of response to EGFR tyrosine kinase inhibitors are needed. So far, genomic screening for EGFR mutations has been based on direct sequencing, single-strand confirmation polymorphism analysis (7) or denaturating high-performance liquid chromatography $(8,9)$. Pan et al $(5)$ reported a polymerase chain reaction (PCR)-based assay for the detection of the EGFR exon $21 \mathrm{~L} 858 \mathrm{R}$ mutation that takes advantage of the gain of a Sau961 restriction site created by this mutation. Their assay for exon 19 mutation detection is based on length 
analysis of fluorescently labeled PCR products on an ABI 3100 genetic analyzer.

The aim of this study was to develop two simple PCRbased assays for the detection of the EGFR exon 19 (codons 746-750) deletion and exon 21 point mutation that are fast and easy to perform and do not require special equipment other than thermocyclers.

\section{Materials and methods}

Samples and DNA isolation. Genomic DNA was extracted and pooled from oral mucosa samples of five healthy individuals. This pooled DNA was used as a normal DNA control for the development of the PCR assays. Heterozygous mutant control DNA was extracted from cells of the lung cancer cell lines NCI-H-1650 and NCI-H-1975 (American Type Culture Collection, LGC Promochem, Wesel, Germany). The lung adenocarcinoma cell line NCI-H-1650 contains the heterozygous exon 19 deletion, and the NSCLC cell line NCI-H-1975 contains the heterozygous exon 21 L858R mutation (4). DNA was isolated using the QIAamp DNA Mini Kit (Qiagen GmbH, Hilden, Germany).

Exon 19 deletion assay. To simplify screening for the 15-bp deletion in exon 19 (codons 746-750), a so-called Bi-PASA (10) was designed. Bi-PASA contains 4 primers: i) two allelespecific primers complementary to the diallelic sequence variation in a bi-directional orientation such that both primers terminate at the variation site and ii) two so-called outer primers that anneal at different distances from the sequence variation to differentiate the downstream and upstream reactions on an agarose gel. In this way, the assay has an inherent control, since at least one allele-specific fragment is amplified per reaction (Fig. 1). Forward and reverse primer design should result in PCR amplicons of a size easily amplified and resolved by agarose gel electrophoresis, and primers should have a reasonable GC content, similar melting temperatures $(\mathrm{Tm})$, and be free of interfering secondary structures. Finally, specificity and yield in the one-tube reaction were optimized.

Exon 21 L 858 point mutation assay. The basis for discrimination using allele-specific PCR is that a PCR primer mismatched at its 3 '-end with the DNA template will react less efficiently than one that is entirely complementary. Allele-specific primers, A and B, were designed with mismatches at their 3'-end, A complements the normal allele $(2573 \mathrm{~T})$ and $\mathrm{B}$ complements the mutant allele $(2573 \mathrm{G})$. A consensus primer $(\mathrm{P})$, was designed in the sense direction within exon 21 (Software IDT SciTools, Integrated DNA Technologies, Coralville, USA). As an internal control for each PCR reaction, forward (HGHf) and reverse (HGHr) primers for human growth hormone $(H G H)(11)$ were included within the reaction. The exon $21 \mathrm{PCR}$ assay involves two reactions: i) the 'T-reaction', containing HGHf and HGHr, the $5^{\prime}$ consensus primer $\mathrm{P}$, and the primer A complementary to the normal EGFR allele; ii) the 'G-reaction' containing HGHf and HGHr, P, and the primer B complementary to the mutant EGFR allele (Fig. 2). For testing and proving the specificity of the allele-specific PCR primers A and B, a

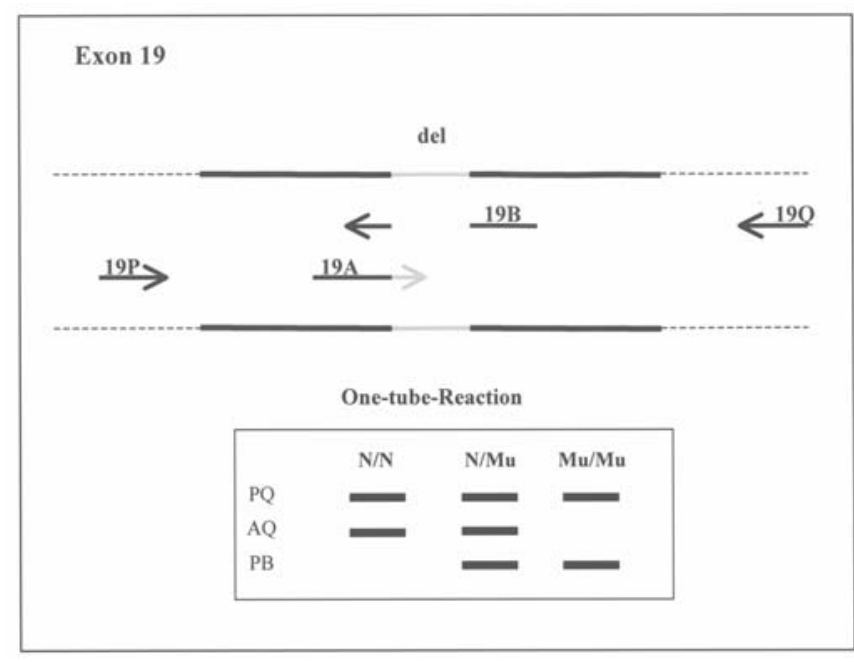

Figure 1. Scheme of the Bi-PASA assay for the detection of the exon 19 deletion. The deletion sequence variation in exon 19 is indicated by a light gray line. The four primers, two outer primers $\mathrm{P}$ and $\mathrm{Q}$, and two allelespecific inner primers $\mathrm{A}$ and $\mathrm{B}$, are represented by arrows. $\mathrm{P}$ and $\mathrm{Q}$ anneal at different distances from the deletion. The PQ fragment is always amplified and serves as an internal reaction control. The inner primer A matches a part of the deletion sequence at its 3'-end. The AQ fragment can be amplified only with the wild-type sequence. The inner primer B matches the mutant DNA sequence containing the 15-bp deletion, i.e. PB can be amplified only in mutant DNA. A heterozygous genotype $(\mathrm{N} / \mathrm{Mu})$ is characterized by both an AQ and PB amplification fragment.

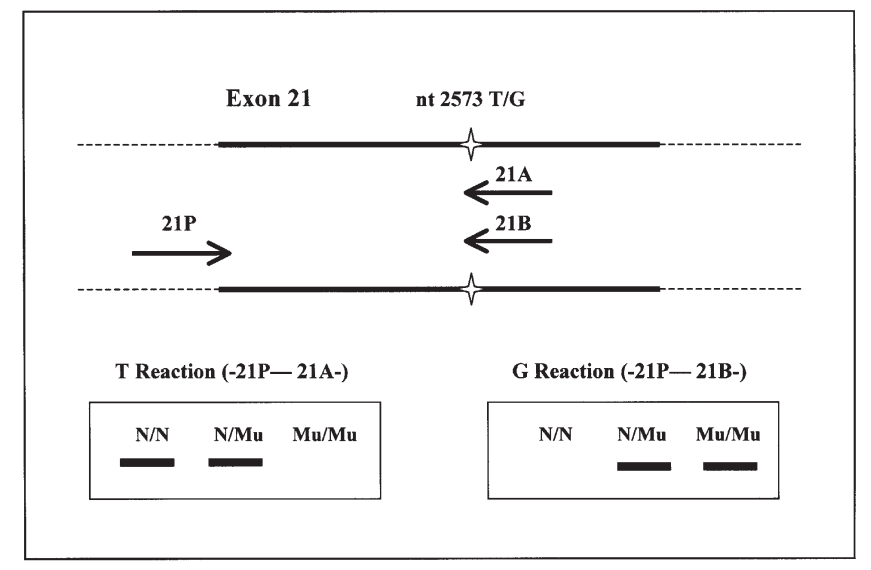

Figure 2. Scheme of the allele-specific PCR assay for the detection of the exon 21 point mutation. Exon 21 and the adjacent exon/intron boundary is depicted. The location of the nt $2573 \mathrm{~T}>\mathrm{G}$ point mutation is indicated by an asterisk. The forward orientation of the consensus primer (21P) and the reverse position of each of the sequence specific primers (21A and 21B) are illustrated by arrows. The 'T-reaction' contains the consensus primer $\mathrm{P}$ and the primer $21 \mathrm{~A}$ complementary to the normal EGFR exon 21 allele. Amplification occurs only with the normal allele as template. In the 'G-reaction', which contains primer $21 \mathrm{P}$ and primer $21 \mathrm{~B}$ complementary to the mutant allele, amplification occurs only with the mutant allele as template. A heterozygous genotype $(\mathrm{N} / \mathrm{Mu})$ is characterized by an amplification fragment in both T- and Greactions.

homozygous mutant control sample was created artificially, because no homozygous mutant DNA sample was available. This was necessary since the cell line NCI-H-1975 contains the exon 21 point mutation in a heterozygous state. For creating this mutant/mutant control, 2 primers, $21 \mathrm{p} 3$ and $21 \mathrm{~d} 2$ were designed with $21 \mathrm{~d} 2$ complementary to the mutant allele 
Table I. Primer sequences and PCR parameter.

\begin{tabular}{|c|c|c|c|c|}
\hline & Primer & Primer sequences ( $\left.5^{\prime}-3^{\prime}\right)$ & $\begin{array}{c}\text { Optimal primer } \\
\text { concentration }(\mu \mathrm{mol} / \mathrm{l})\end{array}$ & $\begin{array}{l}\text { Amplicon size } \\
\text { (bp) }\end{array}$ \\
\hline \multirow[t]{4}{*}{ Bi-PASA exon 19} & 19P & GTAACATCCACCCAGATCACTG & 0.25 & PQ: 444 \\
\hline & $19 Q$ & GTGTCAAGAAACTAGTGCTGGG & 0.25 & AQ: 325 \\
\hline & $19 \mathrm{~A}$ & CCCGTCGCTATCAAGGAATTAA & 0.25 & PB: 134 \\
\hline & 19B & GTTGGCTT-TCGGAGATGTT-TTGATAG & 0.25 & \\
\hline Allele-specific PCR & $21 \mathrm{P}$ & AGGGTCTTCTCTGTTTCAGGGCAT & 0.1 & \\
\hline \multirow[t]{2}{*}{ exon 21} & $21 \mathrm{~A}$ & TTC CGC ACC CAG CAG TTTGGCTA & 0.1 & PA: 137 \\
\hline & 21B & CGC ACC CAG CAG TTT GGTTC & 0.1 & PB: 134 \\
\hline \multirow[t]{2}{*}{$\mathrm{HGH}$} & HGHf & TGCCTTCССАACСАТТСССТTA & 0.2 & 434 \\
\hline & $\mathrm{HGHr}$ & CCACTCACGGATTTCTGTTGTGTTTC & 0.2 & \\
\hline \multirow[t]{2}{*}{ Sequencing exon 19} & $19 \mathrm{p} 2$ & AATATCAGCCTTAGGTGCGG & 0.1 & \\
\hline & $19 \mathrm{q} 2$ & CAGTAATTGCCTGTTTCCAGCC & 0.1 & \\
\hline \multirow[t]{2}{*}{ Sequencing exon 21} & $21 \mathrm{p} 3$ & TGATGATCTGTCCCTCACAGCA & 0.1 & \\
\hline & $21 \mathrm{~d} 1$ & TCCTCATTCACTGTCCCAGCAA & 0.2 & \\
\hline \multirow{2}{*}{$\begin{array}{l}\text { Creating Mut/Mut control } \\
\text { exon } 21\end{array}$} & $21 \mathrm{p} 3$ & TGATGATCTGTCCCTCACAGCA & 0.1 & 160 \\
\hline & $21 \mathrm{~d} 2$ & ACCCAGCAGTTTGGCCCGC & 0.1 & \\
\hline
\end{tabular}

(2573 G) at its 3'-end (Table I). DNA of the cell line NCI$\mathrm{H}-1975$ was amplified with these primers, resulting in a 160-bp PCR fragment containing the $2573 \mathrm{G}$ point mutation. The diluted PCR fragment was used as a mutant/mutant template control for the establishment of the exon 21 point mutation assay.

PCR. For both mutation detection assays, the PCR conditions were optimized for high specificity (i.e. detection of only the normal or only the mutant allele), high sensitivity (i.e. no spurious PCR fragments), and acceptable yield. A series of annealing temperatures $\left(52-60^{\circ} \mathrm{C}\right)$, primer concentrations (0.1-0.4 $\mu \mathrm{mol} / \mathrm{l})$, and $\mathrm{Mg}^{2+}$ concentrations (1.5-3.5 mmol/l) were tested. All PCR reactions were run at a final volume of $25 \mu 1$. Reactions consisted of: $80-100 \mathrm{ng}$ genomic DNA; $200 \mu \mathrm{mol} / 1 \mathrm{dNTP} ; 0.1-0.25 \mu \mathrm{mol} / \mathrm{l}$ of primers; $1.5 \mathrm{mmol} / \mathrm{l}$ $\mathrm{MgCl}_{2} ; 0.5 \mathrm{U}$ Taq polymerase (Roche Diagnostics, Penzberg, Germany). Final cycling conditions were: 5 min of denaturing at $94^{\circ} \mathrm{C}$ and 30 cycles of $94^{\circ} \mathrm{C}$ for $0.30 \mathrm{~min}$, annealing $58^{\circ} \mathrm{C}$ (exon 19) or $60^{\circ} \mathrm{C}$ (exon 21) for $45 \mathrm{sec}$ and $72^{\circ} \mathrm{C}$ for $1 \mathrm{~min}$. A volume of $10 \mu \mathrm{l}$ of the PCR products was electrophoresed on a standard $2 \%$ agarose gel stained with SYBR-Green I for visualization under UV light.

Sequencing. In order to prove the specificity of the allelespecific primers, EGFR exons 19 and 21 from normal and mutant control DNA were PCR-amplified. The PCR products were purified with the MinElute PCR Purification Kit (Qiagen). Genomic sequencing (MWG Biotech, Penzberg, Germany) was performed using the appropriate downstream PCR primer or additionally designed sequencing primers. Primer sequences are indicated in Table I, and all sequencing reactions are depicted schematically in Figs. 3 and 4.

\section{Results}

Allele-specific PCR primers were designed with the aid of Oligo software, and PCR conditions were tested. Final primer sequences and PCR parameters found to be essential for successful mutation screening are listed in Table I. The EGFR exon 19 deletion assay and the exon 21 point mutation assay analyzed by agarose gel electrophoresis and SYBR-Green staining are shown in Figs. 3A and 4A, illustrating the predicted amplification pattern for normal and mutant genotypes.

For the exon 19 deletion assay, a rapid one-tube PCR method with 4 primers was developed. The two outer primers ( $\mathrm{P}$ and $\mathrm{Q}$ ) were placed on the opposing strands at pre-defined bases, resulting in an amplicon of $444 \mathrm{bp}$ as internal standard. Because $\mathrm{P}$ and $\mathrm{Q}$ were designed to anneal at different distances from the deletion, a gel-based differentiation of the downstream and upstream PCR reaction with the inner primers is possible. The 3'-end of allele-specific inner primer A matches a part of the deletion sequence, i.e. the AQ fragment is only amplified in the case of the wild-type sequence. The inner primer B matches the mutant DNA sequence containing the deletion, i.e. PB can be amplified only in homozygous mutant DNA. A heterozygous genotype $(\mathrm{N} / \mathrm{Mu})$ is characterized by both a 325-bp AQ- and a 134-bp PB amplification fragment (Fig. 3A). Parameters important for designing the 4 Bi-PASA primers were the melting temperature (with Tm values of A and B lower than that of the PQ segment) and the annealing temperature (relatively high to avoid hybridization between the multiple PCR products). The primer specificity was confirmed by genomic sequencing of the purified PCR fragments (Fig. 3B).

For the detection of the exon $21 \mathrm{~L} 858 \mathrm{R}$ point mutation, sequence-specific primers $21 \mathrm{~A}$ and $21 \mathrm{~B}$ of 20 and $23 \mathrm{nt}$, 


\section{A}

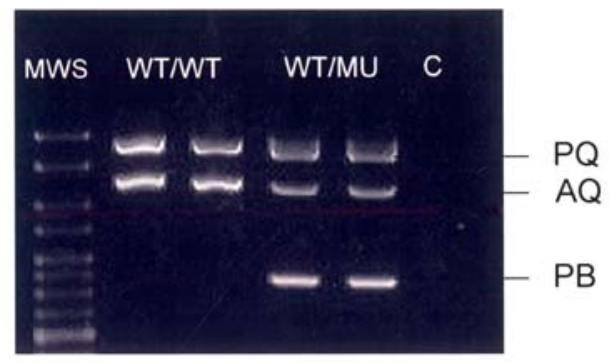

$B(1)$

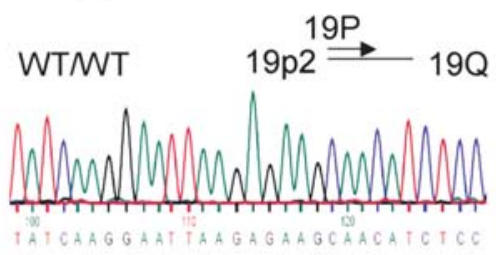

$B(2)$

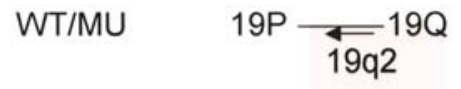

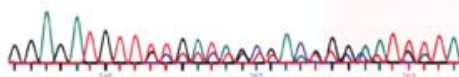

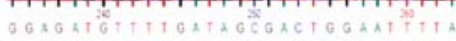

$B(4)$

$\mathrm{B}(3)$

WT/MU

$19 \mathrm{p} 2 \stackrel{19 \mathrm{P}}{\longrightarrow} 19 \mathrm{~B}$

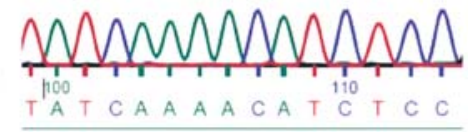

Figure 3. Exon 19 Bi-PASA assay and sequencing results. A, PCR analysis of the 15-bp deletion in wild-type/wild-type normal controls (lanes 2 and 3) and in the lung adenocarcinoma cell line NCI-H-1650 containing the heterozygous deletion (lanes 4 and 5). Lane 1, molecular weight marker; lane 6, no template PCR control. B(1), Part of exon 19 sequence of a homozygous wild-type normal control DNA amplified with primers 19p2 and 19Q and sequenced with primer 19P. All primer sequences are indicated in Table I. B(2), EGFR exon 19 sequence of NCI-H-1650 DNA amplified with primers 19P and 19Q and sequenced with primer 19q2. The depicted fragment contains the heterozygous 15-bp deletion. B(3), Sequencing result of the AQ fragment amplified from heterozygous mutant DNA (sequenced with primer 19q2). AQ contains the wild-type sequence [compare to B(1)]. B(4), Sequencing result of the PB fragment amplified from heterozygous mutant DNA (sequenced with primer 19P). Because the inner primer B matches the mutant DNA, the PCR fragment contains the 15-bp deletion.

A

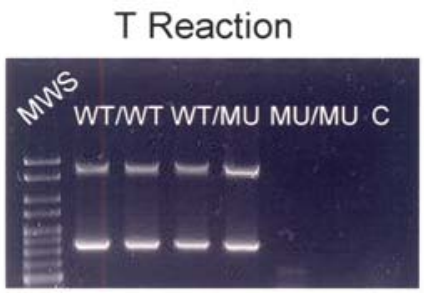

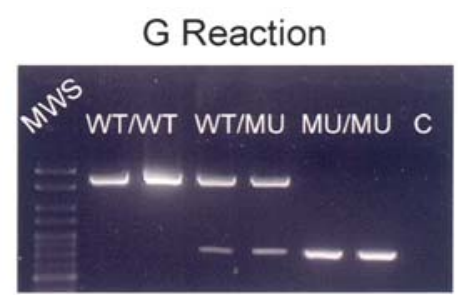

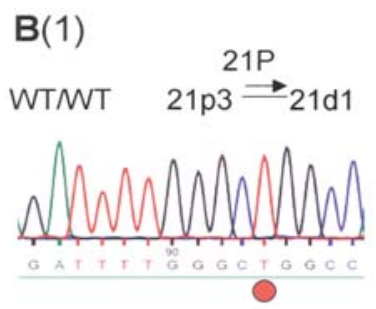

$\mathbf{B}(2)$

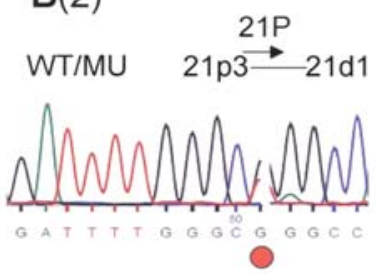

B(3)
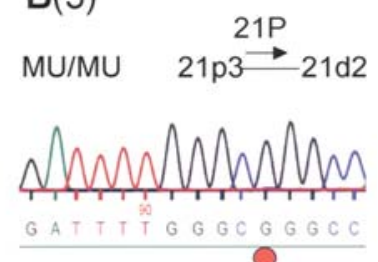

Figure 4. Exon 21 L858R allele-specific PCR assay and sequencing results. A, PCR was performed in a two-tube-reaction. The normal genotype (T/T) is characterized by a 137-bp fragment in the 'T-reaction' only. The heterozygous genotype (T/G) has this fragment in both, the 'T-' and the 'G-reaction'. The homozygous mutant genotype $(\mathrm{G} / \mathrm{G})$ is characterized by a 134-bp fragment in the 'G-reaction' only. The HGH PCR control product (434 bp) is amplified in all reactions in which the template is DNA. It is not seen in the amplification of the mutant/mutant control (PCR fragment). The 'no template control' is labeled as ' $\mathrm{C}$ '. B(1), Exon 21 sequence containing the L858R point mutation locus (depicted by a dot), homozygous wild-type DNA amplified with primers $21 \mathrm{p} 3$ and $21 \mathrm{~d} 1$ and sequenced with primer 21P. All primer sequences are indicated in Table I. B(2), The cell line NCI-H-1975 contains the heterozygous exon 21 L858R mutation (depicted by a dot). Sequencing was performed as in B(1). B(3), A homozygous mutant (G/G) control was artificially created by PCR (see Materials and methods) and sequenced with primer 21P. The fragment contains the point mutation at a homozygous state (dot). 
respectively, were designed in the antisense direction. At the 3 '-end of the allele-specific primers, one (21A) or two (21B) further mismatches were added in order to weaken hydrogen bonding between primer and template and therefore increasing the likelihood of discrimination. The consensus primer $\mathrm{P}$ was designed in the sense direction overlapping the intron 20-21/ exon 21 boundary. The primer specificity was confirmed by genomic sequencing of the PCR fragments (Fig. 4B). The presence of a 434-bp fragment was used as an internal control for each PCR reaction following ampification by forward and reverse $H G H$ primers.

For both mutation detection assays, the PCR conditions were optimized with the aim of high specificity (i.e. detection of only the normal or only the mutant allele), high sensitivity (i.e. no spurious PCR fragments), and acceptable yield. A series of annealing temperatures, primer concentrations, and $\mathrm{Mg}^{2+}$ concentrations were tested with pooled genomic DNA and tumor DNA isolated from the cell lines containing the mutation.

\section{Discussion}

Because of its universal availability as a standard methodology in molecular medicine, we designed EGFR mutation screening assays based on PCR. Our protocols allowed discrimination of allele-specific PCR fragments by agarose gel electrophoresis without the need of capillary electrophoresis devices and without a restriction fragment length polymorphism assay. With our assays, the specificity was incorporated into the amplification reaction itself. Interpretation of the results could be made by simple visual inspection of the stained gel to determine whether or not a specific primer pair amplified a fragment with the template DNA.

Allele-specific PCR, also known as Amplification Refractory Mutation System (ARMS) is a well established method for discriminating between different alleles at specific loci resulting from single base mutations $(12,13)$. We used the methodology to establish two assays: one for a single base change (exon 21) and one for a small deletion of $15 \mathrm{bp}$ (exon 19). For both the point mutation and the deletion detection, the most important step was designing allelespecific PCR primers that were able to specifically discriminate wild-type and mutant DNA.

For assay design, we had to solve the problem of having no homozygous mutant control DNA because EGFR mutations have been found in a heterozygous status, both in patient samples and in the lung cancer cell lines NCI-H-1650 and NCI-H-1975. Consequently, these 'mutant' controls contain one wild-type allele and are not suitable to entirely control the allele-specificity of the primers, especially in the case of a point mutation in which it is demanded that one single base pair change is discriminated. There are several possible experimental approaches for creating artificially constructed mutation samples, including sample spiking, transfection, and genetic engineering, through such techniques as homologous recombination and site-directed mutagenesis (14). However, these techniques are time-consuming and laborintensive and require some expertise with recombinant DNA techniques. For the exon 21 L858R point mutation, we created artificially by PCR a homozygous mutant control fragment and were able to validate the primer specificity and to establish appropriate PCR conditions. Creating a similar control fragment simply by PCR was technologically not possible in the case of the 15 bp deletion in exon 19. But our assay design as a Bi-PASA with two outer and two inner primers ensures the discrimination between the normal and the mutant allele because the allele-specific inner primers involve the deletion. In practice, for screening patient samples, both our assays are able to easily and specifically detect the heterozygous EGFR mutation status.

Our protocols provide a rapid, sensitive, and cost-effective EGFR screening method for large sample numbers. Their application in lung cancer management could help in finding treatment strategies for patients presenting with a new diagnosis of NSCLC and those with disease progression after initial chemotherapy. Both PCR protocols should be appropriate for overall screening for EGFR mutation analysis in patients with moderate to well differentiated lung adenocarcinoma. In America or Europe, at least $10 \%$ of lung adenocarcinoma contain EGFR mutations (5), and $90 \%$ of these will be detectable using the two PCR assays described herein. Among exon 19 mutations, few 9-, 12-, 18- and 24-bp deletions have been detected, and by far the most common deletion size was $15 \mathrm{bp}(5)$.

PCR results should be confirmed by direct sequencing as the gold standard for mutation detection. If the result of both screening assays is negative, analysis can be continued based on direct sequencing of exons 18,20 , and 21 to detect the remaining $10 \%$ of potential EGFR mutations.

\section{References}

1. Lynch TJ, Bell DW, Sordella R, Gurubhagavatula S, Okimoto RA, Brannigan BW, Harris PL, Haserlat SM, Supko JG, Haluska FG, Louis DN, Christiani DC, Settleman J and Haber DA: Activating mutations in the epidermal growth factor receptor underlying responsiveness of non-small-cell lung cancer to gefitinib. N Engl J Med 350: 2129-2139, 2004.

2. Paez JG, Janne PA, Lee JC, Tracy S, Greulich H, Gabriel S, Herman P, Kaye FJ, Lindeman N, Boggon TJ, Naoki K, Sasaki H, Fujii Y, Eck MJ, Sellers WR, Johnson BE and Meyerson M: EGFR mutations in lung cancer: correlation with clinical response to gefitinib therapy. Science 304: 1497-1500, 2004

3. Sequist LV, Joshi VA, Janne PA, Muzikansky A, Fidias P, Meyerson M, Haber DA, Kucherlapati R, Johnson BE and Lynch TJ: Response to treatment and survival of patients with non-small cell lung cancer undergoing somatic EGFR mutation testing. Oncologist 12: 90-98, 2007.

4. Sordella R, Bell DW, Haber DA and Settleman J: Gefitinibsensitizing EGFR mutations in lung cancer activate anti-apoptotic pathways. Science 305: 1163-1167, 2004.

5. Pan Q, Pao W and Ladanyi M: Rapid polymerase chain reactionbased detection of epidermal growth factor receptor gene mutations in lung adenocarcinomas. J Mol Diagn 7: 396-403, 2005.

6. Sequist LV, Bell DW, Lynch TJ and Haber DA: Molecular predictors of response to epidermal growth factor receptor antagonists in non-small-cell lung cancer. J Clin Oncol 25: 587-595, 2007.

7. Marchetti A, Martella C, Felicioni L, Barassi F, Salvatore S, Chella A, Camplese PP, Iarussi T, Mucilli F, Mezzetti A, Cuccurullo F, Sacco R and Buttitta F: EGFR mutations in nonsmall-cell lung cancer: analysis of a large series of cases and development of a rapid and sensitive method for diagnostic screening with potential implications on pharmacologic treatment. J Clin Oncol 23: 857-865, 2005.

8. Chin TM, Anuar D, Soo R, Salto-Tellez M, Li WQ, Ahmad B, Lee SC, Goh BC, Kawakami K, Segal A, Iacopetta B and Soong R: Detection of epidermal growth factor receptor variations by partially denaturing HPLC. Clin Chem 53: 62-70, 2007. 
9. Cohen V, Agulnik JS, Jarry J, Batist G, Small D, Kreisman H, Tejada NA, Miller WH Jr and Chong G: Evaluation of denaturing high-performance liquid chromatography as a rapid detection method for identification of epidermal growth factor receptor mutations in nonsmall-cell lung cancer. Cancer 107: 2858-2865, 2006.

10. Liu Q, Thorland EC, Heit JA and Sommer SS: Overlapping PCR for bidirectional PCR amplification of specific alleles: a rapid one-tube method for simultaneously differentiating homozygotes and heterozygotes. Genome Res 7: 389-398, 1997.

11. Chen EY, Liao YC, Smith DH, Barrera-Saldana HA, Gelinas RE and Seeburg PH: The human growth hormone locus: nucleotide sequence, biology, and evolution. Genomics 4: 479-497, 1989.
12. Sarkar G, Cassady J, Bottema CD and Sommer SS: Characterization of polymerase chain reaction amplification of specific alleles. Anal Biochem 186: 64-68, 1990

13. Newton CR, Graham A, Heptinstall LE, Powell SJ, Summers C, Kalsheker N, Smith JC and Markham AF: Analysis of any point mutation in DNA. The amplification refractory mutation system (ARMS). Nucleic Acids Res 17: 2503-2516, 1989.

14. Jarvis M, Iyer RK, Williams LO, Noll WW, Thomas K, Telatar M and Grody WW: A novel method for creating artificial mutant samples for performance evaluation and quality control in clinical molecular genetics. J Mol Diagn 7: 247-251, 2005. 